\title{
Effect of Mixed Crops on Soil Plant Parasitic Nematodes in Lettuce Cultivation (Lactuca sativa L.)
}

\begin{abstract}
Background: Lettuce (Lactuca sativa L.) is an annual plant with very rapid growth and a major species in the assortment of leafy vegetables. Plant parasitic nematodes are economically important pests of leafy vegetables in monoculture and intensive organic fertilization. The simultaneous cultivation of several plant species in the same area can overcome the disadvantages of crops from homogeneous crops. The purpose of this work is to determine the quantitative changes in soil nematode communities in the joint cultivation of medicinal and vegetable species.

Methods: The experiments were carried out in a vegetation house. To create mixed crops, the plants the lettuce (Lactuca sativa L.), cutivar 'Bohemia', tagetes (Tagetes sp. L.), basil (Ocimum basilicum L.), calendula (Calendula officinalis L.) summer savory (Satureja hortensis L.) and arugula (Eruca sativa L. Cav.) were used.

Result: The results of the nematological analysis showed a decrease in the number of nematodes when mixed growing of lettuce with arugula, calendula and tagetes. The mixed growing of lettuce and calendula resulted in a significant reduction in nematodes, with a $\mathrm{Pf} / \mathrm{Pi}$ value of 0.3 . As a result of the decrease in the nematode population, there was an increase in lettuce yields when mixed grown with arugula and calendula, compared to when grown alone. The study of plant parasitic nematodes based on comparative evaluation of different combinations of plants shows that combinations of crops can be applied as a control method in integrated plant protection systems.
\end{abstract}

Key words: Container experiment, Lactuca sativa, Mixed farming, Nematodes.

\section{INTRODUCTION}

The aim of the production of lettuce (Lactuca sativa L.) is to increase yields and produce environmentally friendly produce. Plant parasitic nematodes are dangerous pests on leafy vegetables. Yield losses caused by plant parasitic nematode are increasing due to restrictions on the use of chemical fumigants and the removal of certain nematicides from the market (Jones, 2017; Roberts, 2018). As a result, there is increasing interest in the development and application of ecological methods for the management of nematodes. The current alternative practices include application of mixed cultures. Growing two or more crops at the same time in the same place (intercropping) leads to an increase in diversity in the agroecosystem (Reddy, 2017). In literature, there are numerous examples demonstrating the higher efficiency of heterogeneous agrocenoses. These combinations prevent the emergence and development of pests, as well as help increase abundance of natural enemies (Parthiban et al. 2018). The suppressive effect of Tagetes spp. on nematodes has been reported more than 80 years ago (Steiner, 1941). Tyler (1938) reported that 29 tagetes varieties are resistant to root-knot nematodes (Meloidogyne spp.). The more recent literature is dominated by information on the mechanisms of nematocidal activity of mixed crops. These mechanisms may occur individually or in combination, leading to a lower abundance of nematodes. The allopathic effect is due to plant metabolites or their products, which are released into the microenvironment and are toxic to other organisms (Hooks et al. 2010; Nehad
Institute of Soil Science, Agrotechnologies and Plant Protection 'Nikola Pushkarov', Sofia, Bulgaria.

Corresponding Author: Lilyana Koleva, Department of Plant Protection, University of Forestry, Kliment Ohridsky Blvd 10, 1797 Sofia, Bulgaria. Email: liljanakoleva.Ik@gmail.com

How to cite this article: Koleva, L. and Mitova, I. (2021). Effect of Mixed Crops on Soil Plant Parasitic Nematodes in Lettuce Cultivation (Lactuca sativa L.). Indian Journal of Agricultural Research. 55(6): 756-760. DOI: 10.18805/IJARe.A-622.

Submitted: 17-02-2021 Accepted: 29-04-2021 Online: 31-07-2021

et al. 2017). However, despite huge amount of research activities (Malézieux et al. 2009; Osei et al. 2016) and the established wide range of plant species that inhibit the development of nematodes, they cannot be so easily applied in the strategies for integrated crop protection (IPM). Mixed components must be carefully selected to be biologically useful.

This study was undertaken to investigate whether mixed crop cultivation is important for the sustainable management of nematodes in integrated and organic lettuce production, identifying quantitative changes in soil nematode communities in the joint cultivation of medicinal and vegetable species.

\section{MATERIALS AND METHODS}

The experiment was planted in the second half of April 20182020 under controlled conditions in a vegetation house of Institute of Soil Science, Agrotechnologies and Plant 
Protection, Sofia, Bulgaria using a lettuce (Lactuca sativa L.) cultivar 'Bohemia'. The plants tagetes (Tagretes sp. L.), basil (Ocimum basilicum L.), calendula (Calendula officinalis L.), summer savory (Satureja hortensis L.) and arugula [Eruca sativa (L.) Cav.] were used to create mixed crops. The experiment was embedded in $3 \mathrm{~L}$ containers and contained 8 variants with 3 replicates. The soil was an alluvial-meadow soil (Fluvisol), suitable for growing leafy vegetables. The manure used was bovine, well decomposed, meeting the phytosanitary and biological requirements of the crop. The soil to manure weight ratio in the experiment is $5: 1$. The study also included a compost substrate variant (Rindstrup group) with $28 \%$ organic "C" and a balanced macronutrient content.

The following variants were tested: control variant: soil with lettuce plants $(\mathrm{SL})$; control variant: soil+manure with lettuce plants (SML); soil+manure with lettuce plants+ arugula $(S M L+A)$; soil+manure with lettuce plants+calendula $(\mathrm{SML}+\mathrm{C})$; soil manure with lettuce plants+tagetes $(\mathrm{SML}+\mathrm{T})$; soil + manure with lettuce plants+savory $(\mathrm{SML}+\mathrm{H})$; soil + manure with lettuce plants+basil $(S M L+B)$; compost substrate with lettuce plants (CSL). In the test containers, 3 lettuce plants and 3 tagetes, calendula, savory, basil or arugula plants were planted. In variants SL, SML and CSL containing only soil, soil+manure and substrate, only lettuce plants are planted.

\section{Nematological analysis}

The soil samples were mixed and with the help of a measuring cylinder was made an average sample of 100 $\mathrm{cm}^{3}$. The determination of an average sample of $100 \mathrm{~cm}^{3}$ is important because the density of different soil substrates is different. When examining plant samples taken from the root system, not only endoparasitic nematodes were covered, but also endoparasitic species. A quantity of $30 \mathrm{~g}$ of roots was sufficient for the pooled samples. The Cobb method and the modified Baermann funnel method were used to extract the mobile stages of the nematodes. Until quantitative determination of the nematodes, the samples were refrigerated for no longer than 14 days after extraction. The nematode fluid was supplemented to $100 \mathrm{ml}$ with water, to cover the total number of isolated individuals. The resulting suspension was stirred with a magnetic stirrer and transferred to a Bogorov Modified Counting. Under a stereomicroscope at $40 \times$ magnification, all nematodes are initially enumerated and when recounted, plant parasitic nematodes are removed. The average number of live nematodes extracted was determined by Peters (2013).

\section{Studied vegetative parameters}

Phenological observations and biometric measurements of lettuce plants were performed: plant height $(\mathrm{cm})$, root weight (g/plant), leaf mass (g/plant), total plant mass (g/plant).

\section{Statistical analysis}

Statistical processing of the results obtained was prepared with the statistical product STATGRAPHICS 18, ANOVA.

\section{RESULTS AND DISCUSSION}

The higher number of nematodes before the start of the experiment were detected in soil + manure substrate (SM), followed by soil (S) resp. 1498.4 and 991.8 nematodes in $100 \mathrm{~cm}^{3}$ of soil substrate. The lowest was the number of nematodes in the compost substrate (CS)-304.8 nematodes per $100 \mathrm{~cm}^{3}$ (Fig 1).

Within the experiment "lettuce-medicinal and vegetable crops" significant differences in the final number of nematodes after mixed vegetation were observed. Statistical analysis of the data shows differences between the variants (Table 1). The total nematode abundance of the control variants was significantly higher than that of the mixed lettuce cultivation variants. For lettuce grown individually in soil and soil + manure, the final number of nematodes was 896.8 ind $100^{-3}$ resp. 1198.4 ind $100^{-3}$. After the experiment, it was found that the number of nematodes increased in variants $S L$ and SML; there was almost no

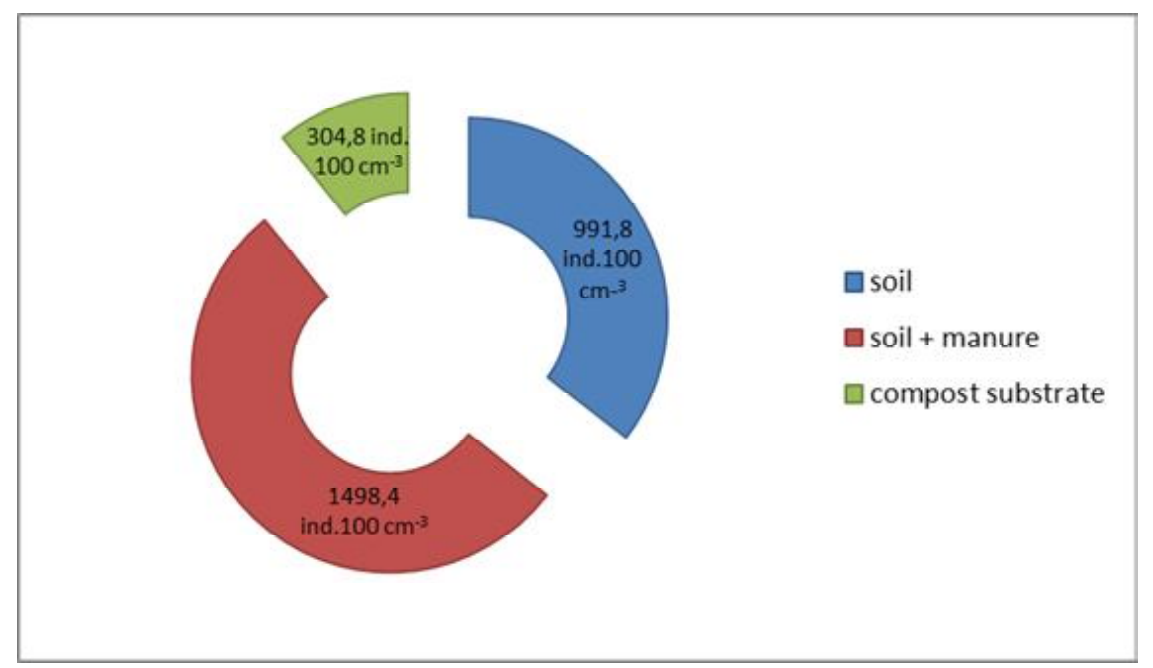

Fig 1: Number of nematodes in the soil substrates used before the vegetation of the mixed crop. 
Table 1: Changes in vegetative parameters and number of nematodes in lettuce cultivation together with medicinal and vegetable species.

\begin{tabular}{|c|c|c|c|c|c|c|}
\hline Variant & $\begin{array}{l}\text { Plant } \\
\text { height } \\
(\mathrm{cm})\end{array}$ & $\begin{array}{c}\text { Root } \\
\text { weight } \\
\text { (g/plant) }\end{array}$ & $\begin{array}{l}\text { Leaf } \\
\text { mass } \\
\text { (g/plant) }\end{array}$ & $\begin{array}{c}\text { Total plant } \\
\text { mass } \\
\text { (g/plant) }\end{array}$ & $\begin{array}{c}\text { Number of soil } \\
\text { nematodes } / 100^{3} \\
\text { substrate after } \\
\text { joint vegetation }\end{array}$ & ${ }^{*} \mathrm{Pf} / \mathrm{Pi}$ \\
\hline SL & $8.30 a$ & $1.19 b$ & $5.46 a$ & $6.65 a$ & $896.8 a$ & $2.1 \mathrm{~b}$ \\
\hline SML & $12.53 d$ & $1.13 b$ & $9.66 \mathrm{~d}$ & $10.80 \mathrm{~d}$ & $1198.4 b$ & $4.5 a$ \\
\hline$S M L+A$ & $9.67 \mathrm{ba}$ & $1.82 d$ & $11.24 \mathrm{e}$ & $13.06 \mathrm{e}$ & $680.4 c$ & $0.9 \mathrm{~d}$ \\
\hline$S M L+C$ & $21.33 f$ & $2.96 f$ & $11.22 \mathrm{e}$ & $14.18 \mathrm{f}$ & $428.4 d$ & $0.3 \mathrm{~g}$ \\
\hline$S M L+T$ & $10.97 \mathrm{~b}$ & $0.95 a b$ & $6.84 b$ & $7.80 \mathrm{~b}$ & $462.4 d$ & $0.6 f$ \\
\hline$S M L+S$ & $14.77 \mathrm{c}$ & $1.30 c$ & $8.33 c$ & $9.63 c$ & 492.0df & $1.1 \mathrm{c}$ \\
\hline$S M L+B$ & $14.67 \mathrm{c}$ & $0.63 a$ & $5.78 a$ & $6.41 a$ & $559.2 f$ & $1.1 \mathrm{c}$ \\
\hline CSL & $10.27 \mathrm{~b}$ & $1.34 \mathrm{c}$ & $8.71 \mathrm{c}$ & $10.05 d$ & $414.8 d$ & $1.2 \mathrm{c}$ \\
\hline
\end{tabular}

(Mean \pm SE; different letters $=$ Stat. difference; $\mathrm{P}<0.05$; Tukey test).

${ }^{*} \mathrm{Pi}$ - Number of nematodes before vegetation; Pf - Number of nematodes after vegetation.

change in the variants $S M L+S, S M L+B, C S L$, while a decrease in the number of plant parasitic nematodes was observed when grown together with lettuce, calendula and tagetes. The mixed cultivation of lettuce and calendula resulted in a significant reduction in nematodes, with a $\mathrm{Pf} /$ $\mathrm{Pi}$ value of 0.3 being statistically significantly lower than the other variants: arugula 0.9 and tagetes 0.6. The effect of the mixed crops was the same in the variants lettuce + savory and lettuce+basil. The value of the Pf/Pi ratios was 1.1 .

The analysis of the results of the vegetative parameters, given in Table 1, confirms the reporting changes in nematode populations. At an average height of $12.81 \mathrm{~cm}$ for the experimental plants, the lettuces with calendula were $66.5 \%$ higher and those developed together with savory and basil resp. $15.3 \%$ and $14.5 \%$. There are statistically proven differences in plant height between the lettuces in the control variant and all other variants except for the arugula variant $\mathrm{SML}+\mathrm{A}$. The plants developed jointly with arugula (11.24 g/plant) and calendula (11.22 $\mathrm{g} /$ plant) have the largest leaf mass exceedingly significantly that of the other variants. With an average above-ground test mass of $8.41 \mathrm{~g} /$ plant, the excess in variants $S M L+A$ and $S M L+C$ was 33.7 and $33.4 \%$, respectively. The leaf mass of the other mixed-growing lettuces ranges between 5.78 and $8.71 \mathrm{~g} / \mathrm{plant}$. The differences between the arugula variant and those with tagetes and savory, as well as between the lettuce containers grown with calendula and those with tagetes and savory, are highly proven. The lettuces of the variant grown together with calendula also have the most developed root system, 2.96 $\mathrm{g} / \mathrm{plant}$, in line with the well-developed above ground part of the plant. The measured root mass of these plants was more than twice the average (1.42 $\mathrm{g} / \mathrm{plant})$ for the test. Lettuce plants from basil containers have the least developed roots $0.63 \mathrm{~g} / \mathrm{plant}$. There are highly significant differences in the root mass of lettuces between the calendula containers and the variants with compost substrate, tagetes, savory and basil. As a result of the decrease in the number of nematodes, there was an increase in lettuce yields when mixed grown compared to when they were grown alone. The total average weight of the plants in the study was $9.82 \mathrm{~g} /$ plant. The variant with calendula, with the highest plants, also had the highest total plant mass of $14.18 \mathrm{~g}$ or $44.4 \%$ heavier plants compared to the average total mass of lettuce plants in the experiment. For lettuces grown with arugula, no large masses of $13.06 \mathrm{~g}$ (33\% more than the average total mass) were accounted for, despite their low height. However, there was a slight decrease in lettuce yield when grown together with basil $6.41 \mathrm{~g}$ total mass ( $34.7 \%$ less than the average total mass), tagetes $(7.80 \mathrm{~g} ; 20,5 \%$ less than the average total mass) and savory ( $9.63 \mathrm{~g} ; 1.9 \%$ less than the average total mass). This is anticipited because the different plants share nutrients and space in the same nutrient volume. Statistically, the differences between the calendula variant and the compost, tagetes, savory and basil variants are well represented. Although the results of the influence of the soil substrate on the vegetative parameters of lettuce were not discussed in detail here, then during the experiment, differences in the root masses of lettuces between the experimental and control variants with compost and manure were also proved statistically. Similar results have been observed by other authors, who assess the growth and physiological characteristics of lettuce in the delivery of different $\mathrm{N}$ organics and prove that the fertilizers derived from animal manure give good effects on leaves, LAI, the rate of photosynthesis and biomass lettuce (Slamet et al., 2017).

Due to the complexity of the process involved in determining the species affiliation of nematodes and the multivariate of the experiment, individuals from nematode communities were analysed only quantitatively. In addition, some nematode species have a very short life cycle and reproduce rapidly and changes in the soil environment can cause significant changes in the species structure (Villenave, 2001).

The results obtained here are close to those reported by Tringrovska et al. (2015). In mixed crops the possibilities for growing tomatoes with tagetes, ustard, basil and lettuce 
under greenhouse conditions were evaluated. The mustard and the tagetes suppress the attack by nematodes, the genus Meloidogyne, but the mustard causes a decrease in the yield of tomatoes. No negative impact on the yield and quality of the tomato fruits was found in the tagetes. Tagetis is known to contribute to decrease in the density of nematodes, but the decrease is not as pronounced as in the calendula variant. There are numerous studies on the use of tagetes (Tagetes spp.). Shah et al. (2018) by applying leaf extracts to some medicinal plants prove that margosa or marigold (Tagetes erecta) extract treatment of brinjal seedlings prior to transplantation can avoid severe damage by suppressing the multiplication of root-knot nematodes and inducing the tolerance in treated inoculated plants. Tagetis is well known for its ability to produce compounds such as $\alpha$-terthienyl, which are allelopathic to many species of plant-parasitic nematodes. However, there is contradictory data in the literature about how this compound is released (Hooks et al. 2010).

Our results are in line with the information obtained by other authors, who prove that the role of root exudates in interactions between plant roots and other plants, microbes, and nematodes present in the rhizosphere (Bais et al. 2006). The results are also confirmed by the data reported by Elzawahry et al. (2014) examining the effect of five plant species (Tagetes erecta L., Datura stramonium L., Nerium oleander L., Ipomea palmata L. and Santolina chamaecyparissus L.) on the plant parasitic nematode Tylenchulus semipenetrans under greenhouse and laboratory conditions. The authors prove that the tested plant species reduce the population of $T$. semipenetrans juvenile stages and their effect increases over time, with $T$. erecta giving the lowest percentage of reduction. Interpretation of mechanisms that suppress the development of nematode populations is complex because several mechanisms usually occur simultaneously.

Future research should focus on identifying the exact causes of suppressing the development of nematodes in the mixed intercropping and on developing IPM programs that take advantage of this potential. To confirm the influence of the "hostile" plants used, it is necessary to monitor the populations of nematodes during the subsequent growing seasons and let the lettuces be grown individually in the same soil substrate. Before this system can be recommended for use by farmers, its profitability needs to be significantly better.

\section{CONCLUSION}

The total nematode abundance of the control variants was significantly higher than that of the mixed lettuce cultivation variants. A decrease in the number of nematodes was observed with the joint cultivation of arugula, calendula and tagetes. The mixed cultivation of lettuce and calendula resulted in a significant reduction in nematodes, with a Pf/ $\mathrm{Pi}$-value of 0.3 . Statistically the lowest in comparison with the other variants: with arugula 0.9 and tagetes 0.6. The lettuce plants developed together with arugula and calendula have significantly higher leaf and root mass.
The plants in the variant with calendula ware $66.5 \%$ higher than the average height of the lettuces in the experiment, and those developed together with savory and basil resp. $15.3 \%$ and $14.5 \%$. The obtained data indicate that combinations of crops can be used as a control method in integrated plant protection systems. However, the profitability of this system is yet to be examined before being recommended for use by farmers.

\section{REFERENCES}

Bais, H.P., Weir, T.L., Perry, L.G., Gilroy, S. and Vivanco, J.M. (2006). The role of root exudates in rhizosphere interactions with plants and other organisms. Annual Review of Plant Biology. 57: 233-266.

Elzawahry, A.M., Mahran, A.M.A. and Sallam, M.A. (2014). Management of citrus nematode (Tylenchulus semipenetrans) by certain plant species. Journal of Phytopathology and Pest Management. 1(3): 46-52

Hooks, C.R., Wang, K.H., Ploeg, A. and McSorley, R. (2010). Using marigold (Tagetes spp.) as a cover crop to protect crops from plant-parasitic nematodes. Applied Soil Ecology. 46(3): 307-320.

Jones, R.K. (2017). Nematode control and nematicides: Developments since 1982 and future trends. In Nematology in South Africa: A view from the $21^{\text {st }}$ century. Springer, Cham. 129-150.

Malézieux, E., Crozat, Y., Dupraz, C., Laurans, M., Makowski, D., Ozier-Lafontaine, H., Rapidel B., de Tourdonnet S. and Valantin-Morison M. (2009). Mixing plant species in cropping systems: concepts, tools and models: A review. Agronomy for Sustainable Development. 29: 43-62.

Nehad, A., Abdel-Rehman, A.R., Hanan, H. and Hala, A.K. (2017). Allelopathic activity of some desert plants against plant pathogenic bacteria and nematodes. Journal of Environmental Science. 37(2): 15-35.

Osei, K., Braimah, H., Issa, U.S. and Danso, Y. (2016). Mixed cropping system on diversity and density of plant parasitic nematodes. Journal of Agricultural Science. 8(11): 147.

Parthiban, P., Chinniah, C., Baskaran, R.K., Suresh, K., and Kumar, A.R. (2018). Impact of intercropping system to minimise the sucking pests incidence in groundnut (Arachis hypogaea Linnaeus). Legume Research- An International Journal. 41(5): 788-791.

Peters, A. (2013). Application and commercialization of nematodes. Applied Microbiology and Biotechnology. 97(14): 61816188.

Reddy P.P. (2017). Intercropping. In: Agroecological Approaches to Pest Management for Sustainable Agriculture. Springer, Singapore. 109-131.

Roberts, P.A. (2018). Influence of Nematicides on Nematode Pathogens and their Host Plants. In: Pesticide Interactions in Crop Production. CRC Press. 335-352.

Shah, N.H., Dar, A.R., Qureshi, I. A., Akhter, A., Wani, M.R. and Andleeb, L. (2018). Control of root-knot disease of brinjal (Solanum melongena L.) by the application of leaf extracts of certain medicinal plants. Indian Journal of Agricultural Research. 52(4): 444-447. 
Slamet, W., Purbajanti, E.D., Darmawati, A. and Fuskhah, E. (2017). Leaf area index, chlorophyll, photosynthesis rate of lettuce (Lactuca sativa L.) under N-organic fertilizer. Indian Journal of Agricultural Research. 51(4): 365-369.

Steiner, G., (1941). Nematodes parasitic on and associated with roots of marigold (Tagestes hybrida). Proceedings of the Biological Society of Washington. 54: 31-34.

Tringpovska, I., Yankova, V., Markova, D. and Mihov, M. (2015). Effect of companion plants on tomato greenhouse production. Scientia Horticulturae. 186: 31-37.
Tyler, J. (1938). Proceedings of the root-knot conferences held in Atlanta. Plant Disease Reporter Supplements. 109: 133-151.

Villenave, C., Bongers, T., Ekschmitt, K., Djigal, D. and Chotte, J.L., (2001). Changes in nematode communities following cultivation of soils after fallow periods of different length. Applied Soil Ecology. 17(1): 43-52. 